\title{
O Cinema Documentário da América Latina dos Anos de 1960. Uma Breve Reflexão dos Principais Movimentos Cinematográficos do Novo Cinema da América Latina
}

\author{
Dígo Ivan Caroca Riquelme
}

\begin{abstract}
Resumo: A historiografia da sociedade latino-americana dá especial importância às coincidências entre a política dos movimentos sociais e culturais. Entre as décadas de 1960 e 1970, surgiram novas formas de realização do Cinema Latino-Americano. Nosso objeto de pesquisa são os procedimentos retóricos e ideológicos utilizados por precursores dos principais manifestos da Cinematografia Latino-Americana. Realizamos, para tanto, entrevistas e leituras com a finalidade e objetivo de circunscrever as características singulares do que será o Nuevo Cine Latino-Americano - NCLA. Faremos uma análise reflexiva a partir do conceito de Cinema Moderno, visando não apenas compreender e comparar os momentos destes artistas em vida, mas lançar um olhar não exultante sobre os autores, reiterando a memória consagrada e mantida por seus protagonistas.
\end{abstract}

Palavras-chave: História, Política, Cinema.

\begin{abstract}
The historiography about Latin America's societies gave a special attention to the intertwined relations between political movements and cultural in the 1960's and 1970's. One of those points of entanglement is the cinematographic experiences made by the Latin-American cinema of those decades, especially the Nuevo Cine Latino-Americano (NCL). The main objective of this research is to analyze the rhetorical and ideological procedures used in the realization of this filmography through the reading of the principal manifests related to that Latin-America's particular branch of cinema. Having the same purpose in sight, the interviews of the NCL principal exponents will also be consulted. To understand this production, it will be conducted a reflexive analysis from the concept of "Modern Cinema" to not only compare the lives of these cinemamakers, but - differently from the encomiastic approach that has traditionally been done - to restate a consecrated memory that still is maintained by its own protagonists.
\end{abstract}

Keywords: History, Latin America, political and cinematographic.

$\left({ }^{*}\right)$ Doutor pelo Departamento de Cinema do Instituto de Artes - UNICAMP. Integrante do Centro de Pesquisa de Documentário - CEPIDOC/UNICAMP. E-mail: <caroca@unicamp.br>. Recebido em 3.12.2010 e aceito em 20.6.2011. 


\section{INTRODUÇÃO}

A história serve de inspiração para as diferentes formas de representação. Após a Revolução Francesa e a difusão do Romantismo, ela foi sedimentada nas artes em geral e, com o advento do cinema, houve uma enorme popularização, que permitiu uma diversificação de sua representação muito mais abrangente.

Cabe esclarecer desde o início que um número muito elevado de filmes produzido mundialmente possui o referente histórico. Destacamos aqui especialmente o viés do cinema documentário latino-americano e sua relação com a agitação pré-revolucionária dos anos de 1960. O trabalho procura, portanto, abordar a produção cinematográfica que reflete a realidade do período, porém sob a ótica do autor, enquanto pessoa que se envolve socialmente com o que expressa em película. Não recorremos à análise direta das obras fílmicas - a despeito de sua vital importância para estudos localizados na fronteira entre Cinema (como gênero documentário) e História (gênero político-social). Passamos a uma tentativa de visualizar o campo de atuação teórica e prática sobre o qual o diretor se debruça e cujo "produto" final será o filme ou o documentário.

Neste contexto histórico, os autores latino-americanos — reunidos em grupos ou individualmente - conceberam a atividade cinematográfica como frente de luta ao imperialismo norte-americano, o que pode ser mais importante ainda, também como fonte de (re)educação da consciência e da sensibilidade de si mesmos, bem como de seu povo e de toda uma geração.

De um lado, esses autores recorriam a representações de realidades sociais mais explícitas (ou seja, o oposto do que fazia, por exemplo, o cinema de massa hollywoodiano), enquanto de outro buscavam o experimentalismo entendido como prática social que não tem a intenção de entreter o público, porém de convergir para uma formação em favor de mudanças sociais e de uma "descolonização cultural" dos países em questão, notadamente abundantes de cultura e tradição próprias (sobretudo popular e indígena).

Glauber Rocha e Nelson Pereira do Santos (Brasil), Fernando Birri, Fernando Solanas e Octavio Getino (Argentina), Miguel Littin e Aldo Francia (Chile), Jorge Sanjinés e Jorge Ruiz (Bolívia), Mario Handler (Uruguai), Mauricio Walerstein e Román Chalbaud (Venezuela), Julio García Espinosa, Tomás Gutiérrez Alea e Santiago Álvarez Román (Cuba), entre tantos outros, seriam cineastas políticos do Nuevo Cine Latino-Americano - NCLA, que desenvolveram suas práticas de acordo com circunstâncias e condições estabelecidas pela história de cada país. Não por acaso, documentários, filmes e manifestos aparecem lado a lado em festivais, mostras e congressos, transformando-se em discussões das políticas governamentais - locais ou mundiais - , sendo a América Latina um dos continentes em que o cinema, por meio do NCLA, se engajou social e politicamente de maneira permanente (e isso sem abdicar da preocupação estética).

As tentativas de "descolonização cultural" se identificavam, na década de 1960, com a produção de vários cineastas que viriam a ter importância decisiva no NCLA. O posicionamento destes diretores, antes de tudo, pode ser entendido mediante seus manifestos que passam a constituir parte intrínseca do movimento artístico. Dentro de grandes conotações 
de ativismo político para a transformação de uma sociedade melhor, e enquanto filmam suas produções, os principais cineastas lançaram suas diretrizes em manifestos como: "Hacia un tecer cine: Apuntes y experiencias para el desarollo de un cine de liberación e el Tercer Mundo", do grupo Cine Liberación (liderados por Fernando Solanas e Octavio Getino, na Argentina) e "Uma estética da fome" (de Glauber Rocha, no Brasil), ou o ensaio/manifesto "Por um cinema imperfeito" (de Julio Garcia-Espinosa, de Cuba) e mesmo propostas como "O cinema junto ao povo" (do Grupo Ukamau, na Bolívia).

Todas essas frentes de "ação" cinematográficas pretendiam expandir as práticas locais de realização. Havia, no entanto, um desafio maior, em última instância, comum a todos os autores da América Latina. Segundo Mariana Martins Villaça (2008), este era:

a criação de um novo cinema latino-americano que fosse esteticamente original, consolidasse uma identidade própria no panorama internacional e que tivesse como projeto subjacente a reflexão sobre os problemas peculiares à América Latina como o subdesenvolvimento, o abuso do poder, as grandes desigualdades sociais, o autoritarismo, a luta pela democracia e, tangenciando todas essas questões, o papel do intelectual e do artista nesse contexto. (VILLAÇA, 2008, p. 7.)

Este cinema viria ao encontro ao zeitgeist de novas vozes artísticas do período, representando um verbo novo e único - porque a expressão deste novo cinema exigia e já apresentava uma estética singular de traços regionais. Como afirmou Miguel Littin (1990):

(...) se expressara em uma fulgurante literatura, em uma música que resgatara na memória popular os acordes das canções liberada; em um novo cinema que encontrara nas confrontações sociais, nas imagens e no som que liberaram antigas ataduras estéticas e subordinadas a tecnológicas, empurrada a crescer pela força crescente de uma história que exigia ser narrada com urgência. (LITTIN, 1990, p. 85.)

A base comum desses cineastas estaria em suas origens, trabalhadas sobretudo no discurso cinematográfico, com referências estéticas do realismo social. Além das teorias de artes gerais, e essencialmente politizadas, as principais referências seriam o neorealismo italiano, a montagem soviética, o documentário inglês e a nova onda francesa.

Na prática, essa influência estética estaria diretamente relacionada com a questão política mundial, uma vez que, se analisados de perto, não existiam diferenças profundas entre os conflitos sociais que estavam acontecendo em toda a América Latina (desde os carvoeiros no Chile até os mineiros na Bolívia) e outros continentes menos desenvolvidos do período (a exemplo da África e da Ásia).

É fato que, no caso da América Latina, as tradições culturais encontravam pontos comuns que iam além da língua espanhola oficial em todos os países (obviamente, com exceção do Brasil). Além das políticas locais, que sofriam etapas semelhantes, os meios de comunicação, até então precários, e as perseguições políticas dificultavam os contatos entre os países, contribuindo para o cotidiano conturbado, a repressão ideológica e a escassez de fundos.

Segundo Rodrigues (2009), a revolução cubana — liderada por Che Guevara e Fidel Castro, na segunda metade da década de 1950 - representava a semente mais segura do 
socialismo, revelando a esperança em forma de igualdade entre os países que formavam a América Latina. A influência do "sucesso revolucionário" de Cuba trazia o desejo de troca de experiências cinematográficas, alcançadas por esses jovens cineastas políticos latino-americanos, que também alimentavam tentativas de alianças artísticas. Estas começaram então a tomar forma e foram crescendo nos festivais de cinema independentes.

Algumas trajetórias isoladas pontuam e exemplificam o surgimento de um novo panorama cinematográfico no continente latino. No Uruguai, o cinema ganhou cada vez mais espaço desde a década de 1940, quando se desenvolveu no país uma estrutura equivalente às indústrias cinematográficas de grande porte, como viria a ocorrer com a Argentina e o Brasil na década de 1950 .

Durante esses anos, foram realizadas inúmeras coproduções entre Uruguai e Argentina, para as quais se instalaram, neste primeiro país, laboratórios de revelação de película. Com este exemplo, é possível divisar a importância de um trabalho conjunto. Ainda de acordo com Rodrigues (2009),

(...) enquanto a produção na Argentina peronista se encontrava diretamente vinculada ao Estado, o Uruguai passou a ser uma alternativa próxima e neutra, na qual os custos eram mais baixos e não havia controle político sobre a produção. (RODRIGUES, 2009, p. 14.)

O resultado mais visível, em relação à expansão do cinema na América Latina, seriam o surgimento de novos cineclubes e cinematecas. No caso pioneiro do Uruguai:

(...) a Universidade da República contribuiu criando o Instituto de Cine Cientifico (ICUR), o que não só estimulou o consumo e contato com o cinema, como aumentou a qualidade dos filmes. Nesse contexto foram criados: o Festival de Cine Internacional Documental e Experimental de SODRE (Serviço Oficial de Difusão Radioelétrica), desde 1954; e o Primeiro Congresso de Cineastas Latino-americanos Independentes, organizado em 1958 pela mesma instituição. (RODRIGUES, 2009, p. 14.)

O importante é atentar para o fato de que, nos dois encontros, participaram nomes que viriam a se destacar como principais integrantes do Novo Cinema Latino, como o diretor de cinema Fernando Birri pela Escuela Documental de Santa Fé, na Argentina, e o diretor brasileiro Nelson Pereira do Santos, um dos precursores do Cinema Novo no país.

De um terreno neutro, a capital uruguaia - Montevidéu — veio a se tornar espaço promissor para que ocorresse uma das primeiras reuniões informais dos cineastas latino-americanos em seu próprio continente. Antes, encontros como estes só ocorriam em festivais estrangeiros como, por exemplo, em Cannes, Veneza ou Pesaro, na Europa.

Depois do Uruguai, vale lembrar que o Chile, por intermédio do Cine Club de Viña del Mar, dirigido pelo diretor Aldo Francia, foi responsável pelo festival que reuniu filmes e cineastas inovadores e da mesma estirpe. Nesse país, em especial, verificou-se a presença da delegação cubana, graças a acordos com a OEA (Organização dos Estados Americanos), uma vez que o governo chileno, como todos os governos da América Latina (com exceção do México), havia cortado relações diplomáticas com Havana. 
Foi assim que o cinema documentário e experimental latino-americano mobilizou e reuniu atores, escritores, autores e realizadores em torno do processo de mudanças sintomáticas, frente ao momento que a América Latina estava atravessando.

Dito isso, a tentativa de se estabelecer uma determinada compreensão dos acontecimentos e da experiência cinematográfica, portanto, nos levou a fazer uma análise do desenvolvimento e da forma como se construiu o filme documentário, enfocando particularmente os aspectos históricos e o resgate da cultura regional, isto é, tratando o gênero documentário como fonte de documentação e meio de representação.

O cinema documentário é um testemunho da sociedade que o produziu e, assim sendo, uma fonte documental para a ciência histórica, por excelência. Enfatizamos que nenhuma produção cinematográfica está livre dos condicionamentos sociais de sua época, o que nos possibilita afirmar que todo filme é passível de ser utilizado enquanto documento.

No entanto, fazer uso científico de uma forma afirmativa de comunicação requer cuidados especiais. A forma como o filme reflete a sociedade não é, em hipótese alguma, direta, e jamais se apresenta de maneira organizada (i. e., em circuitos lógicos e coerentes), mesmo que assim o aparente. Isso vai de encontro com o estudo aqui proposto: ao privilegiarmos os documentos escritos e a bibliografia existente acerca do tema, pretendemos pôr em destaque uma das inúmeras questões de interesse comum para uma geração de cineastas que fez, da atividade de reflexão, essencialmente, parte orgânica de seu fazer artístico.

Na maior parte destes cineastas, embora a capacidade (e generosidade, pode-se dizer) de explorar o gênero documental e os seus recursos expressivos mediante pesquisa sobre a problemática social já estivesse presente há muito tempo, a obra documental se consolidou a partir da década de 1960 no desenvolvimento das correntes estéticas, narrativas e temáticas originadas nas discussões de ideias advindas das escolas da Europa.

Para efeito de análise, retomamos as teorias e métodos de trabalhos desenvolvidos pelos documentaristas e autores do cinema latino-americano. Sabendo que autores e entrevistados conduziram o objetivo de recriar o cinema pelo olhar do que pode ser realidade ainda hoje, para o espectador (e também para o leitor) este cinema evoca uma memória complexa. Isto porque contém um imaginário que pode ser constatado na base da formação cultural compartilhada por gerações de argentinos, brasileiros, chilenos, cubanos, etc. Uma vez que viveram em consonância com suas várias influências, diversas manifestações e proclamações de independência cultural se mesclaram com manifestos e ideias nacionalistas transformadas em bandeiras de lutas, bem como de produção mais atualizada e criação de novas formas de expressão, especificamente a do cinema.

Dessa forma, pode-se afirmar que o "filme histórico", como detentor de um discurso sobre o passado, coincide com a "História" (entendida como oficial) no que concerne à sua condição discursiva. Não é absurdo considerar que o cineasta, portanto, ao realizar um filme de gênero histórico, assume a posição de historiador, ainda que não carregue consigo o rigor metodológico do trabalho historiográfico.

O grande público, hoje em dia, tem mais acesso ao que chamamos de "História" por meio das mídias visuais do que pela via da leitura e do ensino nas escolas secundárias, 
por exemplo. Essa é uma verdade incontestável no mundo contemporâneo. A imagem domina as esferas do cotidiano urbano, individual ou mesmo em grupos. Esse fato, em grande medida, se deve à existência e à popularização dos "filmes históricos".

No entanto, tais filmes encontram uma grande reação negativa por parte do público "culto" - incluindo uma boa parcela dos historiadores —, que enxerga nessas produções apenas um meio de vulgarização desta História, o que não constitui, em sua totalidade, uma crítica verdadeira. É possível se posicionar contra essa postura sem nenhum temor, pois o historiador não deve menosprezar e muito menos ficar à margem desse processo de difusão do saber histórico por intermédio do cinema, visto que, no entender do autor deste trabalho, atualmente, também a televisão e as diversas mídias podem ser aproveitadas em seu enorme potencial (que pode ser documental ou didático), se aplicado ao ensino da História, a fim de contribuir para o desenvolvimento de uma leitura cinematográfica da história, por exemplo, por um viés eficiente e formador de conhecimento científico e de consciência histórica.

Mônica Almeida Kornis (1992) sustentou que somente a análise do documento respeitado enquanto fonte primária permite que a memória coletiva recupere sua própria história, propiciando ao historiador usá-lo cientificamente, ou seja, com pleno conhecimento de causa. Se tomarmos a ideia de que o documento escrito retrata uma história, por conseguinte o filme registraria a realidade. Lembramos que, já no início da década de 1920, surgiram indícios de que alguns historiadores passaram a reconhecer o cinema como fonte de conhecimento histórico.

Segundo Matuszewski (apud KORNIS, 1992), o filme era sempre visto como registro da realidade. Não entrando em detalhes, no momento, a respeito do debate da pesquisadora, a discussão propriamente metodológica em relação ao "cinema-história" passou a existir então mediante o ponto central da natureza da imagem como cinema. Tal relação pode se fortalecer também ao se concordar com o reconhecimento do valor do documentário que prevalece na discussão dos cineastas e teóricos da década de 1960. Kornis (1992), citando Marc Ferro (em seu artigo "O filme, uma contra-análise da sociedade?"), reafirma a expectativa histórica no documentário, visto a dedicação de Ferro visando demonstrar que o filme, ainda que não faça parte do chamado universo mental do historiador, é um documento que serve para analisar as sociedades.

Com os avanços tecnológicos e científicos alcançados desde o fim do milênio, em especial no domínio da comunicação, modificaram-se bastante os tipos de relações sociais empreendidas pela humanidade como um todo. Desta Nova Era, se esboça, com contornos ainda indefinidos, o cientista social enquanto realizador, o qual não pode se distanciar das ideologias da comunicação, sob o risco de ficar inteiramente fora da realidade do processo histórico em curso. Nesse sentido, assiste-se ao surgimento de uma necessidade histórica imperativa para as ciências que estudam o homem e as suas relações: sua modernização por meio da integração com os novos recursos da comunicação e, neste caso em particular, com o cinema.

Isso posto, o presente trabalho procura, por meio de artigos, livros, manifestos e escritos especializados no documentário, abordar o cinema também no contexto histórico geral, entendido pelos olhares que, comprometidos com a realidade, farão parte da elaboração 
das análises e questionamentos que conduzem o tempo passado e presente. Atualizando as experiências de conteúdo no tempo, certamente pode-se resgatar parte da história dos anais da cultura do cinema latino-americano, ou seja, este material presta-se a esclarecer questões sobre o contexto histórico da época, assim como pode oferecer subsídios para projetos futuros. No fundo, também é impossível pensar no nosso passado histórico sem admitir a imagem cinematográfica como parte integral dos diversos pontos de vista bibliográficos, sejam eles anteriores ou contemporâneos.

\section{O INÍCIO DA UTOPIA}

É fato que, tendo como tema central o conteúdo político-social, diversos cineastas buscaram receitas possíveis para a representação da América Latina dentro da pluralidade de referências estéticas. Além dos próprios filmes, houve ainda uma vasta informação escrita capaz de detectar anseios comuns em suas tentativas de definição dos objetivos do NCLA. O esforço por responder à violenta realidade do continente, que se desnudava perante suas lentes, não se deteve quando os realizadores foram pressionados pelos acontecimentos políticos ou pela escassez de recursos. Ao contrário, este cinema (que é chamado num primeiro momento de cinema "político-militante") se constituiu de um engajamento explícito: uma lógica de mensagem-interlocutor ininterrupta.

Contudo, a expressão "cinema político-social" melhor se encaixa na presente proposta de análise, uma vez que são pesquisadas as obras de denúncias sociais e de tomadas claras de posição — seja do próprio autor ou mesmo pela encomenda — isto é, as intenções puramente didáticas ou ainda de denúncias que, em um determinado aspecto social, passam a ser antipolíticas por excelência.

Pode-se dizer então que a trajetória da busca de um cinema próprio para as Américas Central e do Sul ganhou seu primeiro impulso no Centro Sperimentale di Cinematografia de Roma, na Itália, frequentado nos anos de 1950 por jovens como Julio García Espinosa, Tomás Gutiérrez Alea, Fernando Birri e outros cineastas latino-americanos, os quais compartilharam uma formação comum, cujos frutos se notaram a priori nas décadas de 1960 e de 1970 .

Dentre as referências presentes nessa formação, destacavam-se: o neorrealismo italiano, o cinema épico de Sergei Eisenstein e, em boa medida, o neossurrealismo de Luis Buñuel, a nouvelle vague francesa e o free-cinema inglês. As tendências estéticas presentes na produção europeia, aliadas à busca de afirmação da "latino-americanidade" — em termos políticos e culturais - resultaram numa eclética combinação que integrou a forma para a matéria-prima do que viria a ser o NCLA.

Este cinema nasceu como oportunidade de pôr em prática na América Latina uma proposta de trabalho de produção, métodos de realização e de experimentação de conhecimentos com recursos adquiridos por meio das experiências dos diversos autores que retornaram depois da referida estada em Roma, a partir de 1955 (sobretudo Fernando Birri, Tomás Gutiérrez Alea e Paul Leduc). Para o espectador comum, em sua maioria alheio à história do cinema dos anos de 1960 (como também ao cinema da América Latina), surgiram durante 
esta década muitos artistas que passaram a tomar uma posição de resistência inovadora e integrativa do significado de realização e coprodução audiovisual. Nas palavras de Canclini (1997):

A partir da década de 1960 e começo de 1970 desenvolve-se na América do Sul uma integração solidária de encontros e discussões sobre as diversas temáticas da cultura e da sociedade que estava se constituindo na política mundial. Surge assim, o primeiro encontro de cineastas latino-americanos que se realizou em Viña del Mar, no Chile (1967), e logo em Medellín, na Colômbia (1968). A partir de então, constituem-se pontos de referência para uma nova forma de enfocar o cinema adotando uma moral social mais de acordo com os tempos, esquecendo o cinema de entretenimento alienante e começando a produzir um cinema de compromisso com a realidade latino-americana. (CANCLINI, 1997, p. 215.)

Aldo Francia, médico e cineasta chileno, foi o responsável por organizar o primeiro encontro e festival de cinema em Viña del Mar, supondo que apenas existiam manifestações dispersas, isto é, casos isolados do cinema social representados, por exemplo, pelos já existentes Cinema Novo Brasileiro, Escola Argentina de Santa Fé e pelo incipiente cinema revolucionário de Cuba. Francia confessa que, na ocasião, "desgraciadamente, ignorábamos quienes eran los cineastas del cine joven y el costo real de un evento de esta envergadura". Tal encontro acabou por reunir os principais realizadores de filmes de diversos países latino-americanos, dando início ao que logo seria conhecido como Nuevo Cine Latino-Americano.

Se o problema do custo da realização de festivais já se fez superar pela própria iniciativa dos autores (espécie de bandeira de luta, já por si mesma), por seu lado, a produção fílmica também se beneficiou artisticamente por meio das superações tecnológicas pioneiras.

Percebeu-se que, para os autores do NCLA, o "novo" já era entrevisto não por meio de uma câmera ultramoderna, mas, antes de tudo, da própria consciência de vida nova vida que muda e se transforma a cada momento - e da ética que todo cineasta e indivíduo traz em si. Dentro da contingência da novidade, a ética parece ser a única característica capaz de definir a tão ansiada forma "nova" (i. e., original).

Entendendo que um filme novo nasce apenas de dentro para fora como um todo, o exemplo do que se considera novidade surgiu em meio a manifestações populares na Universidade no Chile, o Cine Nuevo y Experimental; Cine Independente, no México; no "Cine Nuevo", no Uruguai; com sua Cinemateca de Tercer Mundo, no "Cine Documental" colombiano; no cinema de Margot Benacerraf, na Venezuela. Todos esses autores trabalharam a questão da cultura nacional visando à perspectiva de abertura democrática. Este condicionamento envolveu a questão econômica juntamente com a política, o que fez dos autores (e suas ideias e ações apresentadas também mediante textos) um fenômeno de importância internacional em seu nível de compromisso. A afirmação de Nichols (2005) sobre o documentário social se aplica nesta realidade fílmica latino-americana:

Os documentários de representação social proporcionam novas visões de um mundo comum, para que as exploremos e compreendamos. [...] A interpretação é uma questão de compreender como a forma ou organização do filme transmite significados e valores. (NICHOLS, 2005, p. 27.) 
Dentro dessa nova dimensão, na qual o Cinema Documentário ganhou outra nomenclatura (e horizontes) - Cinema Verdade, Cinema Direto —, a montagem acabou também por se modificar. Esta se tornou mais fluída ao privilegiar o tempo do nascimento de pensamentos e ações; tornou-se menos expressiva e mais interna, ao respeitar a conjugação das movimentações de câmera diante de improvisos e imprevistos - sem, contudo, perder a noção de síntese, objetividade, ritmo, experimentação e criação artística.

Neste processo, estabeleceram-se as similaridades e as correspondências, no parentesco existente do formato e dos manifestos do "Cinema Urgente" de Santiago Alvarez (Cuba), "Fotos-documentários" de Fernando Birri (Argentina), o "Cinema Popular" de Nelson Pereira dos Santos (Brasil), "Cinema Novo" de Glauber Rocha, "Tercer Cine" de Fernando Solanas ou "Cine Imperfecto" de Julio Garcia Espinoza (Cuba). A cultura da imagem tornou-se a ferramenta por intermédio da qual artistas e escritores manifestaram suas ideias e falaram para o povo, propondo conteúdos reais e criando por meio da denúncia.

Não por acaso, surgiu igualmente uma literatura - em forma de manifestos, artigos, etc. - para representar os conteúdos filmados em palavras. Como apontou Avellar (1990), as metas de buscar a criação de uma própria linguagem, que fosse libertadora e estimulasse a reflexão e a crítica, que visassem atingir ao grande público e estimular a ideia de uma América Latina como sendo uma Grande Pátria são comumentemente encontradas em obras como os artigos Teoria e Prática do Cinema Latino-Americano (Glauber Rocha) e Hacia un Tercer Cine (Fernando Solanas).

Os manifestos como "A estética da fome" (Brasil), "O cinema de liberação" (Argentina), "O cinema junto ao povo" (Bolívia), "O cinema imperfeito" (Cuba) e "O novo cinema político" (Chile), ao final, se relacionaram diretamente como filmar $e$ documentar, fazendo parte de grandes conotações de ativismo político enquanto atitudes semelhantes e coincidentes nos países da América do Sul.

Conhecer os diretores, correntes, movimentos, experiências que marcaram as décadas de 1960 e de 1970, é refletir sobre as diversas faces do novo cinema latino-americano, plural e diverso em suas escolhas políticas e artísticas, e perceber que isso traz uma nova tentativa de continuar construindo pontes de grandes dimensões geográficas e temporais, que continuaram contribuindo para a formação de milhares de novos olhares, ainda colonizados.

\section{REFERÊNCIAS BIBLIOGRÁFICAS}

AVELLAR, José Carlos. A arte do inconsciente. In: Nossa América, São Paulo, p. 76-84, jul./ago. 1990. CANCLINI, Nestor G. Consumidores e cidadãos. Conflitos multiculturais da globalização. Rio de Janeiro: Editora UFRJ, 1997.

KORNIS, Almeida Mônica. História e cinema: um debate metodológico. In: Estúdios Históricos, Rio de Janeiro, v. 5, n. 10, 1992.

LITTIN, Miguel. O cinema latino-americano e seu público. In: Nossa América, São Paulo,p. 85-87, jul./ago. 1990. 
NICHOLS, Bill. Introdução ao documentário. São Paulo: Papirus, 2005.

RODRIGUES, Lívia Fusco. O envelhecimento precoce do novo cinema latino-Americano. Trabalho de Conclusão de Curso Pós-Graduação em Crítica de Cinema São Paulo. Fundação Armando Álvares Penteado - FAAP. São Paulo, 2009.

VILLAÇA, Mariana Martins. Os acontecimentos de 1968 e seu impacto na produção e circulação do nuovo cine latino-americano. Anais Eletrônicos do VIII Encontro Internacional da ANPHLAC, 2008. 